\title{
Pengaruh Kemampuan Kerja dan Motivasi Tenaga Kerja Suplier Terhadap Kualitas Pelayanan Konsumen
}

\author{
Fransisca Natalia \\ Universitas Bina Sarana Informatika \\ Email : Fransisca.fia@bsi.ac.id
}

\begin{abstract}
Cara Sitasi : Natalia, F. (2019). Pengaruh Kemampuan Kerja dan Motivasi Tenaga Kerja Suplier Terhadap Kualitas Pelayanan Konsumen. Widya Cipta, 3(1), 123-128.
\end{abstract}

\begin{abstract}
This study aims to analyze Effect of Job Skills and Work Motivation to Quality of Service. This research was conducted at PT. Akur Pratama/TOSERBA YOGYA CIKAMPEK focused on labor supplier in the fashion area with a population of about 100 labor supplier and sample 80 respondents drawn at random sampling. The hypothesis was built to examine the influence of several variables and test them on 80 employees at PT AKUR PRATAMA / TOSERBA YOGYA Cab. Cikampek. The population in this study were all suppliers of labor guards at TOSERBA YOGYA Cab. Cikampek, and the number of samples is 80 respondents. The results of this study can be seen that the magnitude of the effect simultaneously between work ability and work motivation on service quality of 0.455 , while the joint contribution to known at 0.207 or $20.7 \%$ while the remaining $18,7 \%$ is influenced by other variables. The results of this study can be seen that there is a significant correlation between the variables of work ability and work motivation on service quality. Variable work ability and work motivation have an influence together with service quality.The results showed that the Job Skills and Work Motivation effect on Quality of Service. So, if PT. Akur Pratama/TOSERBA YOGYA CIKAMPEK want to increase Quality of Service should first improve Job Skill and Work Motivation.
\end{abstract}

Keywords: Job Skills, Work Motivation and Quality of Service.

\section{PENDAHULUAN}

Keberhasilan sebuah perusahaan mencapai tujuan bisnisnya tergantung pada kemampuan untuk menjalankan fungsi pelayanan kepada konsumen hal ini dikarenakan perusahaan merupakan fungsi bisnis yang berhubungan langsung dengan konsumen. Perusahaan menghadapi kesulitan dalam pengambilan keputusan sehubungan dengan makin kompleknya karakteristik konsumen. Perkembangan situasi bisnis sekarang ini sangat dipengaruhi oleh perkembangan arus informasi, teknologi dan tuntutan konsumen yang selalu mengikuti perubahan. Globalisasi yang ditandai dengan adanya arus perdagangan tanpa batas Negara, ruang dan waktu hal ini yang membuat tingkat persaingan semakin tajam.

Dengan adanya tingkat persaingan yang tajam, konsumen dihadapkan pada berbagai pilihan produk yang relatif sama dan sulit dibedakan dengan produk lainnya. Situasi ini membuat konsumen menjadi semakin menuntut nilai produk yang lebih besar, dengan membandingkan antara harga atau sejumlah pengorbanan yang mereka keluarkan dengan manfaat produk yang mereka peroleh. Presepsi konsumen atas nilai berkaitan juga dengan kualitas pelayanan yang mereka terima akan dapat memberikan kepuasan dan dapat tepat memenuhi kebutuhan dan keinginan mereka. Untuk itu perusahaan sekarang berusaha membangun kepuasan konsumen antara lain lewat penyajian kualitas pelayanan kepada pelanggan secara optimal karena pada saat ini perusahaan dituntut untuk lebih mempertahankan konsumen daripada harus mencari konsumen baru. Perusahaan perlu menciptakan hubungan baik dengan konsumen. Antara perusahaan dengan konsumen perlu terdapat suatu hubungan, dimana perusahaan dan konsumen ada saling hubungan. Hubungan ini lebih didasarkan pada suatu relasi dan interaksi antara yang menyediakan atau memberikan produk dengan yang membutuhkan atau menerima produk.

Menurut (Assauri 2004), Kualitas adalah faktorfaktor yang terdapat dalam suatu barang atau hasil yang menyebabkan barang atau hasil tersebut sesuai dengan tujuan untuk apa barang atau hasil itu dimaksudkan atau dibutuhkan". Menurut Stephen P. (Robbins \& Timonthy A. Judge, 2009) Kemampuan 
(ability) berarti "kapasitas seorang individu untuk melakukan beragam tugas dalam suatu pekerjaan". Lebih lanjut, (Stephen P. Robbins \& Timonthy A. Judge 2009) menyatakan bahwa kemampuan keseluruhan seorang individu pada dasarnya terdiri atas dua kelompok dimensi, yaitu :

1. Kemampuan Intelektual (Intelectual Ability), merupakan kemampuan yang dibutuhkan untuk melakukan berbagai aktifitas mental (berfikir, menalar dan memecahkan masalah).

2. Kemampuan Fisik (Physical Ability), merupakan kemampuan melakukan tugas-tugas yang menuntut stamina, ketrampilan, kekuatan, dan karakteristik serupa.

Perusahaan harus memandang penting bagian dari pelayanan ini, karena citra perusahaan serta hubungan atau relasi dengan konsumen ini diharapkan terjalin terus. Selain itu juga pelayanan telah meningkat kedudukannya di mata konsumen menjadi suatu hak, yaitu hak atas pelayanan yang baik atas pilihan terhadap keputusan tetap membangun relasi dengan perusahaan. Kehidupan konsumen yang semakin kompleks menuntut adanya suatu pelayanan yang semakin berkualitas. Pada berbagai kesempatan perusahaan senantiasa menjanjikan pelayanan yang memuaskan kepada konsumen, namun dalam kenyataannya kadang konsumen belum merasakan kualitas pelayanan tersebut diterima secara optimal.

(Hasibuan 2006) menyatakan "Motivasi adalah pemberian daya penggerak yang menciptakan kegairahan kerja seseorang, agar mereka mau bekerja sama, bekerja drivtif dan terintegrasi dengan segala dan upayanya untuk mencapai kepuasan”.

Untuk mengetahui bagaimana tinggi rendahnya kemampuan dan motivasi tenaga kerja supplier bagian fashion di Toserba YOGYA Cikampek dalam pelayanan konsumen dapat diukur dari sejauh mana efektifitas dan efisiensi dalam memberikan pelayanan kepada konsumen. Dengan ini diharapkan kinerja tenaga kerja supplier bagian fashion di Toserba YOGYA Cikampek dalam melayani konsumen dapat meningkat tingkat kepuasan konsumen dalam berbelanja. Faktor yang diperhitungkan dapat meningkatkan gairah kerja tenaga kerja supplier bagian fashion di Toserba YOGYA Cikampek adalah kualitas kemampuan kerja dan motivasi kerja yang dimiliki oleh tenaga kerja supplier bagian fashion. Hal ini cukup beralasan sebab kemampuan dan motivasi kerja merupakan faktor yang mencerminkan sikap dan karakter seseorang dalam melaksanakan tugas pokok dan fungsinya. Kemampuan kerja dan motivasi kerja ini merupakan nilai-nilai yang harus diinternalisasi kepada seluruh para tenaga kerja supplier agar mereka menyadari bahwa mereka adalah pelayan masyarakat, dengan kemampuan dan motivasi yang tinggi, maka tenaga kerja supplier bagian fashion di Toserba YOGYA Cikampek akan melakukan tugastugasnya dengan baik sesuai dengan harapan. Mengingat pentingnya pengaruh faktor kemampuan kerja dan motivasi kerja karyawan terhadap kualitas pelayanan kepada konsumen guna mencapai tujuan perusahaan, maka peneliti melakukan penelitian dalam rangka meneliti faktor-faktor tersebut yang berpengaruh terhadap kualitas pelayanan kepada konsumen.

Berdasarkan informasi yang saya peroleh dari pihak perusahaan Toserba YOGYA Cikampek, menurut pihak Toserba YOGYA Cikampek mereka merasa kualitas pelayanannya sudah baik, tetapi pihak perusahaan ingin saya meneliti faktor apa saja yang mempengaruhi kualitas pelayanan khususnya dibagian fashion. Hal ini bertujuan untuk meningkatkan kualitas pelayanan kepada konsumen agar konsumen tidak berpaling dan tetap menjadi konsumen loyal di Toserba YOGYA Cikampek. Dengan memiliki sumber daya manusia yang professional, loyal, berdedikasi tinggi dan terjamin kesejahteraannya. Menyadari bahwa sumber daya manusia adalah asset yang sangat berarti, yang menggerakan seluruh roda pelayanan, maka pengembangan sumber daya manusia yang teruji kemampuannya, setia pada institusi, bersemangat dalam memberikan pelayanan, niscaya nama Toserba YOGYA Cikampek akan berada dalam benak masyarakat yang akhirnya akan memberikan timbal balik berupa kepuasan pelanggan dan loyalitas pelanggan untuk tetap berbelanja di Toserba YOGYA Cikampek.

Dan melihat kenyataan ini maka penulis tergugah untuk mengangkat masalah kemampuan kerja dan motivasi kerja tenaga kerja supplier terhadap kualitas pelayanan konsumen dalam memberikan kepuasan konsumennya dalam berbelanja, dengan harapan mudah-mudahan berguna dalam hasanah keilmuan dan berguna bagi peneliti sebelumnya, serta implikasi dari tesis ini berguna bagi perusahaan untuk meningkatkan kualitas pelayanan kepada kosumennya sehingga memberikan kepuasan kepada pelanggan dalam berbelanja khususnya yang berbelanja dibagian fashion.

\section{METODOLOGI PENELITIAN}

Desain penelitian ini menggunakan metode kuantitatif dengan menggunakan SPSS no 18 kuisoner akan diberikan kepada responden, data berdasarkan kuisoner akan dilakukan tabulasi dan kemudian dilakukan uji coba instrumen, proses selanjutnya akan dilakukan dengan membuat uji korelasi, uji regresi linier berganda.

Dalam penelitian ini penulis menggunakan metode penelitian kuantitatif, yang terdiri dari variabel 
terikat (dependen) dan varibel bebas (independen) yaitu berupa variabel $\mathrm{Y}$ sebagai variabel terikat dalam hal ini yang menjadi variabel $\mathrm{Y}$ adalah kualitas pelayanan, sedangkan variabel $\mathrm{X}_{1}$ yaitu kemampuan kerja, $\mathrm{X}_{2}$ yaitu motivasi kerja sebagai varibel bebas. Metode ini digunakan untuk mengetahui pengaruh kemampuan kerja dan motivasi kerja terhadap kepuasan pelayanan.

Metode penelitian yang dilakukan adalah metode survey. Data primer dalam penelitian ini adalah data yang diperoleh dengan survey lapangan melalui pembagian kuesioner kepada responden. Data primer adalah data yang berasal langsung dari responden. Data primer dibagi menjadi Data sekunder penelitian ini meliputi berbagai keterangan yang diperoleh berdasarkan literatur-literatur maupun dokumentasi yang dimiliki PT Akur Pratama/TOSERBA YOGYA Cab. Cikampek yang dapat menunjang penelitian ini.

Menurut (Arikunto 2010) "Populasi adalah seluruh subyek penelitian". Jumlah populasi yang akan diteliti dalam penulisan ini adalah para karyawan PT Akur Pratama/TOSERBA YOGYA Cabang Cikampek dengan jumlah populasi sebanyak 100 karyawan.

"Sampel adalah sebagian atau wakil dari populasi yang memiliki karakteristik yang relative sama dan dianggap bisa mewakili populasi” menurut (Arikunto 2002).

Jumlah sampel yang akan diambil dalam melakukan penelitian di PT Akur Pratama/TOSERBA YOGYA Cab. Cikampek adalah 80 orang.

Pengumpulan data penelitian dilakukan dengan menyebarkan kuesioner secara langsung kepada seluruh sampel yang dilakukan dalam jangka waktu satu minggu. Data dari responden didapatkan dari instrumen kuesioner, dengan menggunakan closed questions dimana responden dapat dengan cepat dan mudah menjawab kuesioner, sehingga data dari kuesioner dapat dengan cepat dianalisis secara statistik.

Skala pengukuran yang digunakan adalah skala likert dimana dalam pengisian kuesioner. Menurut (Riduwan 2009) "kuesioner adalah daftar pernyataan atau pertanyaan yang dikirimkan kepada responden baik secara langsung atau tidak langsung". Responden menentukan tingkat persetujuan mereka terhadap suatu pernyataan dengan memilih salah satu dari pilihan yang tersedia. Format yang digunakan untuk menjawab adalah Sangat Setuju (5), Setuju (4), Ragu-ragu (3), Tidak Setuju (2), Sangat Tidak Setuju (1).

Skala likert termasuk skala ordinal dimana operasi matematika tidak berlaku untuk data ordinal. Oleh karena itu perlu merubah datanya menjadi data interval dengan memakai proporsi untuk menentukan nilai dari setiap poin angka ordinal, nantinya proporsi itu yang menjadi dasar besar nilai interval dari nilai ordinalnya. Untuk merubah data ordinal menjadi data interval digunakan metode suksessive interval (Method of Successive Interva/MSIl).

Penelitian ini menggunakan metode eksplanatif yang bertujuan untuk memberikan gambaran mengenai pengaruh antara variabel Kemampuan Kerja dan Motivasi Kerja Tenaga Kerja Supplier terhadap Kualitas Pelayanan.

Tenik yang digunakan dengan menggunakan analisis regresi berganda, yaitu "analisis regresi berganda akan dilakukan bila jumlah variabel independentnya minimal dua" menurut (Ridwan 2009), Uji Parsial Uji (t), Uji Asumsi Klasik dengan menggunakan :

1. Uji Normalitas

2. Uji Homogenitas

Variabel-variabel dalam penelitian ini adalah Kemampuan Kerja, Motivasi Kerja dan KualitasPelayanan.

Tabel 1.

Variabel Kemampuan Kerja

\begin{tabular}{|c|c|c|c|}
\hline Variabel & Dimensi & Sub Dimensi & Nomor butir \\
\hline & \multirow{8}{*}{ Kemampuan Intelektual } & - Kelincahan mental berfikir dari segala arah & $2(1-2)$ \\
\hline & & - Kecakapan & $2(3-4)$ \\
\hline & & - Bekerja Keras & $2(5-6)$ \\
\hline & & - Pantang Menyerah & $2(7-8)$ \\
\hline & & - Mampu Berkomunikasi & $2(9-10)$ \\
\hline & & - Rasa Ingin Tahu Tentang Pengetahuan & $2(11-12)$ \\
\hline & & $\begin{array}{l}\text { - Terbuka dan Menerima Informasi atau Gagasan } \\
\text { Baru }\end{array}$ & $2(13-14)$ \\
\hline & & - Arah Hidupnya Mantap dan Mandiri & $2(15-16)$ \\
\hline
\end{tabular}




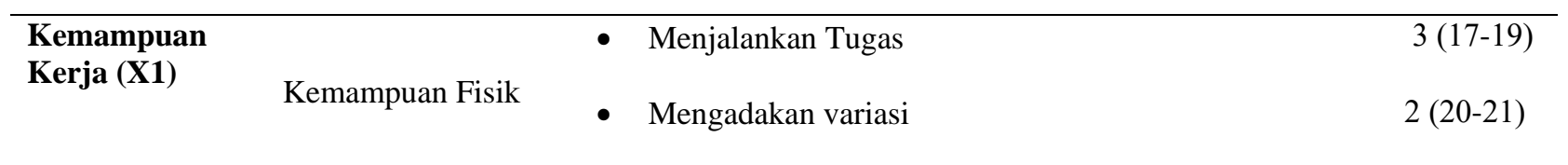

Sumber : Olahan Penulis (2019)

Tabel 2

Variabel Motivasi Kerja

\begin{tabular}{|c|c|c|c|}
\hline Variabel & Dimensi & Sub Dimensi & Nomor butir \\
\hline & & - Gaji yang sepadan & $2(22-23)$ \\
\hline & & - Jaminan Kesehatan & $2(24-25)$ \\
\hline & & - Pemberian Bonus & $2(26-27)$ \\
\hline & & - Jaminan Hari Tua & $2(28-29)$ \\
\hline \multirow{5}{*}{$\begin{array}{c}\text { Motivasi } \\
\text { Kerja (X1) }\end{array}$} & \multirow{5}{*}{$\begin{array}{l}\text { Motivasi Tidak } \\
\text { Langsung }\end{array}$} & - Adanya kebijakan atasan & $2(30-31)$ \\
\hline & & - Adil dalam segala bidang & $2(32-33)$ \\
\hline & & - Rasa aman dalam bekerja & $2(34-35)$ \\
\hline & & - Adanya penghargaan prestasi kerja & $2(36-37)$ \\
\hline & & $\begin{array}{l}\text { - Mengembangkan diri untuk berkarier dan } \\
\text { memperoleh kemajuan }\end{array}$ & $2(38-39)$ \\
\hline
\end{tabular}

Sumber : Olahan Penulis (2019)

Tabel 3

Variabel Kualitas Pelayanan

\begin{tabular}{|c|c|c|c|}
\hline Variabel & Dimensi & Sub Dimensi & Nomor butir \\
\hline \multirow[t]{10}{*}{$\begin{array}{c}\text { Kualitas } \\
\text { Pelayanan }(\mathbf{Y})\end{array}$} & $\begin{array}{l}\text { Keandalan } \\
\text { (reliabilitas) }\end{array}$ & - Kecepatan proses pelayanan & $2(40-41)$ \\
\hline & $\begin{array}{l}\text { Daya tanggap } \\
\text { (responsivitas) }\end{array}$ & - Adil dalam pelayanan & $2(42-43)$ \\
\hline & & - Kesadaran memberikan pelayanan & $2(44-45)$ \\
\hline & & - Menguasai tugas & $2(46-47)$ \\
\hline & Jaminan (assurance) & - Jaminan Pelayanan & $2(48-49)$ \\
\hline & Empaty & - Kepastian hukum & $2(50-51)$ \\
\hline & & - Tahu apa yang dibutuhkan pelanggan & $2(52-53)$ \\
\hline & & $\begin{array}{l}\text { - Memberikan pelayanan yang sesuai selera } \\
\text { pelanggan }\end{array}$ & $2(54-55)$ \\
\hline & Bukti fisik (tangibles) & - Lokasi gedung & $2(56-57)$ \\
\hline & & - Sarana dan prasarana & $2(58-59)$ \\
\hline
\end{tabular}

Sumber : Olahan Penulis (2019) 


\section{HASIL DAN PEMBAHASAN}

Berdasarkan pengujian statistik deskriptif di atas diketahui bahwa dari jumlah sampel yang digunakan responden sebanyak 80 responden semuanya menunjukkan data yang valid.

Hasil Uji Regresi Linier berganda dalam penelitian ini dilakukan dengan bantuan menggunakan program SPSS 17 dan diperoleh hasil sebagai berikut :

\section{Hasil Uji Determinasi}

Koefisien determinasi) $=0.254$ atau $25,4 \%$ hal tersebut menunjukkan bahwa ketiga variabel yaitu kemampuan kerja, motivasi kerja secara simultan atau bersama-sama mampu menjelaskan hubungan dengan variabel kualitas pelayanan kepada konsumen (Y) sebesar 20.7\% sedangkan sisanya dijelaskan oleh variabel yang lainnya.

\section{A. Hasil Uji T}

Diketahui bahwa nilai konstanta a yang diperoleh sebesar 50.535 koefisien arah regresi b1 sebesar 0.297 dan koefisien b2 sebesar 0.224. dari nilai konstanta dari koefiisien arah regresi b1,b2 dapat diperoleh model persamaan regresi :

$\mathrm{Y}=\mathbf{5 0 . 5 3 5}+\mathbf{0 . 2 9 7 X 1}+\mathbf{0 . 2 2 4 X 2}$

Interpretasi dari persamaan regresi linier berganda diatas adalah:

1. Nilai konstanta 50.535 artinya jika kemampuan kerja (X1) dan motivasi kerja (X2) bernilai nol, maka kualitas pelayanan (Y) 50.535 .

2. Koefisien regresi variabel Kemampuan Kerja (X1) menunjukkan nilai positif 0.297. Maka jika kemampuan kerja naik 1 Unit maka Kualitas Layanan akan meningkat 0,297 Unit dengan asumsi Motivasi Kerja tetap.

3. Koefisien regresi variabel Motivasi Kerja (X2) menunjukkan nilai positif 0.224. Maka jika Motivasi Kerja naik 1 Unit maka Kualitas Layanan akan meningkat 0,224 Unit dengan asumsi Kemampuan Kerja tetap.

Pengujian hipotesis ini untuk mengetahui variabel independen (bebas) manakah yang paling dominan pengaruhnya terhadap Kualitas Pelayanan.

Secara rinci dapat dijelaskan sebagai berikut :

a. Kemampuan Kerja $\left(\mathrm{X}_{1}\right)$

Untuk variabel Kemampuan kerja $\left(\mathrm{X}_{1}\right)$ tidak memiliki nilai signifikansi. Nilai Sig $\mathrm{t}>5 \%$ $(0,024>0,05)$. Dengan demikian pengujian Ho ditolak dan $\mathrm{H} 1$ diterima. Hal ini memperlihatkan bahwa Kemampuan kerja $\left(\mathrm{X}_{1}\right)$ berpengaruh signifikan terhadap Kualitas Pelayanan (Y).

b. Motivasi Kerja $\left(\mathrm{X}_{2}\right)$
Untuk variabel Motivasi kerja $\left(\mathrm{X}_{2}\right)$ tidak memiliki nilai signifikansi. Nilai Sig t > $5 \%(0,030>0,05)$. Dengan demikian pengujian Ho ditolak dan $\mathrm{H} 1$ diterima. Hal ini memperlihatkan bahwa Motivasi Kerja $\left(\mathrm{X}_{2}\right)$ berpengaruh signifikan terhadap Kualitas Pelayanan (Y).

Jadi kesimpulan yang dapat diambil berdasarkan pengujian hipotesis diatas adalah variabel Kemampuan Kerja dan Motivasi Kerja berpengaruh secara parsial terhadap Kualitas Pelayanan kepada konsumen.

\section{B. Hasil Uji F}

Berdasarkan hasil perhitungan Uji $\mathrm{F}$ menunjukkan Signifikansi F $=0.000$. Jadi Sig F $<5 \%(0.000<$ 0.05), dengan demikian H1 diterima dan Ho ditolak yang berarti bahwa secara serempak variabel $X_{1}$, $\mathrm{X}_{2}$, mempunyai pengaruh yang signifikan terhadap variabel Y. Jadi terbukti bahwa variabel Kemampuan kerja dan motivasi kerja berpengaruh secara bersama-sama terhadap Kualitas pelayanan.

Berdasarkan hasil pengujian hipotesis diatas bagan penelitian penulis revisi sebagai berikut :

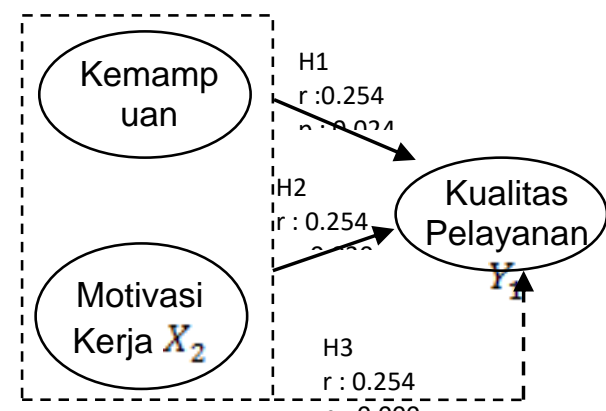

Sumber : Olahan Penulis (2019)

\section{Gambar 1. Bagan yang Direvisi}

\section{KESIMPULAN}

Penelitian ini menghasilkan fakta empiris dimana Kemampuan Kerja berpengaruh positif dan signifikan terhadap Kualitas Pelayanan Kepada Konsumen., Motivasi Kerja berpengaruh positif dan signifikan terhadap Kualitas Pelayanan Kepada Konsumen, Kemampuan Kerja dan Motivasi Kerja secara bersama-sama berpengaruh positif terhadap Kualitas Pelayanan Kepada Konsumen. 


\section{REFERENSI}

Arikunto, S. (2002). Prosedur Penelitian Suatu Pendekatan Praktek. Penerbit Rinek Cipta. Jakarta

Assauri, Sofyan. (2004). Manajemen Pemasaran (Dasar Konsep dan Strategi). Penerbit PT Grafindo Persada. Jakarta

Hasibuan, S.P, Melayu. (2006). Manajemen Sumber Daya Manusia. Bumi Aksara. Jakarta

Riduwan. (2009). Metode dan Teknik Menyusun Tesis. Afabeta. Bandung

Stephen, P., Robbins \& Thimoty A. Judge. (2009). Organizational Behavior. New Jersey : Prentice Hall, Inc

\section{PROFIL PENULIS}

Fransisca Natalia SE, MM - Dosen Tetap di Universitas Bina Sarana Informatika pada Program Studi Sistem Informasi Akuntansi Fakultas Teknologi Informasi, dan sejak tahun 2009 telah bergelut dengan mata kuliah yang menjadi andalannya yaitu Metode Penelitian dan Desain Pengembangan Sistem Informasi Akuntansi pada Universitas BSI Kampus Cikampek Lulusan program S1 di Universitas Sanata Dharma Yogyakarta dengan Program Studi Manajemen dan lulusan Program S2 di Universitas BSI Bandung dengan Program Studi Magister Manajemen. 